\title{
Serious complications associated with regadenoson administration for myocardial perfusion imaging
}

\section{To the Editor,}

The Editorial by Hage and Iskandrian ${ }^{1}$ regarding "Serious complications associated with regadenoson administration for myocardial perfusion imaging: A commentary" (September/October 2014 issue) includes a table as a guide for serious complications associated with regadenoson administration. In the table, the authors reported whether or not each listed event occurs with exercise and/or adenosine and that seizures have not been reported with adenosine. Astellas has received spontaneous post-marketing reports of seizures in patients administered adenosine, and the package insert for Adenoscan ${ }^{\circledR}$ was updated in 2005 to reflect these reports. The current package insert includes "seizure" in the Warnings section. ${ }^{2}$ In addition, there is one published case report of bradyasystole and seizures associated with the use of adenosine to terminate supraventricular tachycardia. ${ }^{3}$ Astellas would like to clarify that seizures can occur following the administration of adenosine, and prescribers should be aware of this risk and prepared to treat if necessary. ${ }^{2}$ The use of methylxanthines (e.g., caffeine, aminophylline, and theophylline) is not recommended in patients who experience seizures in association with adenosine and regadenoson. $^{2}$

Disclosures Therese Kitt and Jeanette Jiang are employees of Astellas Scientific \& Medical Affairs, Inc.
Open Access This article is distributed under the terms of the Creative Commons Attribution License which permits any use, distribution, and reproduction in any medium, provided the original author(s) and the source are credited.

Therese Kitt, $M D$

Jeanette Jiang, PharmD

Astellas Scientific \& Medical Affairs, Inc

1 Astellas Way, Northbrook, IL 60062, USA

therese.kitt@astellas.com

\section{References}

1. Hage FG, Iskandrian AE. Serious complications associated with regadenoson administration for myocardial perfusion imaging: A commentary. J Nucl Cardiol 2014;21:877-9. http://www.ncbi.nlm. nih.gov/pubmed/25156654?dopt=Citation.

2. Adenoscan [package insert]; Northbrook, IL: Astellas, Inc. http://www.astellas.us/docs/adenoscan.pdf.

3. Webster DP, Daar AA. Prolonged bradyasystole and seizures following intravenous adenosine for supraventricular tachycardia. Am J Emerg Med 1993;11:192-4. http://www.ncbi.nlm.nih.gov/ pubmed/8476467?dopt=Citation.

doi:10.1007/s12350-014-0048-5

J Nucl Cardiol 2015;22:395.

$1071-3581 / \$ 34.00$

Copyright $\odot 2014$ The Author(s). This article is published with open access at Springerlink.com. 